\section{Percutaneous suture based device closure of an inadvertent right ventricle perforation following pericardiocentesis}

\author{
Rajesh Vijayvergiya* (D), Yamasandi S. Shrimanth* (D), Ganesh Kasinadhuni* (D), \\ Harkant Singh** (D), Ashish Sharma*** (D), Anish Bhargav* (D), Navjyot Kaur* (D) \\ Departments of *Cardiology, and **Cardio-thoracic Surgery, ***Vascular \\ Surgery, Advanced Cardiac Centre, Post Graduate Institute of Medical \\ Education\&Research; Chandigarh-India
}

\section{Introduction}

Pericardiocentesis is an emerging, lifesaving procedure in patients with cardiac tamponade. Inadvertent right ventricle (RV) perforation during pericardiocentesis is a life-threatening complication, which often requires an open surgical repair (1). There are few case reports about the percutaneous closure of iatrogenic RV perforation (2-7). Here, we describe a patient with iatrogenic RV perforation, who had an unsuccessful attempt of percutaneous closure with a suture based vascular closure device.

\section{Case Report}

A 66-year-old woman presented to the emergency room with progressive dyspnea and cough of 3 weeks' duration. On examination, she had tachycardia, raised jugular venous pressure, pulsus paradoxus, and muffled heart sounds. Echocardiography revealed large pericardial effusion (Fig. 1a), dilated inferior vena cava with reduced respiratory variation, RV diastolic collapse, and exaggerated respiratory variation in mitral and tricuspid inflow, which was suggestive of cardiac tamponade. Echocardiography guided emergency pericardiocentesis through subxiphoid space was planned. Following the needle puncture and aspiration of hemorrhagic fluid from the possible pericardial space, a pigtail catheter was positioned through a $6 \mathrm{~F}$ sheath. As continuous aspiration yielded fresh blood without any decrease in pericardial fluid on echocardiography, there was a suspicion of iatrogenic RV perforation. Echocardiography confirmed the position of the pigtail catheter in the RV (Fig. 1b and 1c). She was urgently shifted to the catheterization laboratory. Fluoroscopy confirmed iatrogenic RV perforation with the pigtail being positioned in the main pulmonary artery (Fig. 2a). Another subxiphoid puncture was performed to place a pigtail catheter in pericardial space, and approximately $1 \mathrm{~L}$ of hemorrhagic fluid was aspirated to relieve the tamponade. Following pericardiocentesis, she had hemodynamic improvement and was stable. There was no further accumulation of blood in the pericardial space in the next 12 hours.

The cardiothoracic team was consulted for open surgical repair of RV perforation. Following discussion with the cardiothoracic team, the patient, and her relatives, written informed consent was obtained for percutaneous closure of RV perforation, along with the standby support of the surgical team for emergency open repair.

Under local anesthesia, a pulmonary artery pigtail catheter was exchanged with a $0.035, " 150 \mathrm{~cm}$ long guidewire and positioned at the distal left pulmonary artery. Over the wire, a Perclose ProGlide ${ }^{\mathrm{TM}}$ suture-based device, Perclose ProGlide ${ }^{\mathrm{TM}}$ (Abbott Vascular, Santa Clara, CA, USA), was tracked through RV perforation site to the pulmonary artery (Fig. $2 b$ and $3 a$ ). Following removal of the guidewire, the device was pulled back till back bleeding from the device lumen stopped. At this position, a suture knot was tied and trimmed by the Perclose knot pusher and trimmer (Fig. 2c). Immediately after the percutaneous intervention, echocardiography showed the gradual accumulation of blood in the pericardial space, which was drained with the pigtail catheter in situ. The patient was immediately shifted to the operation theatre, where a midline thoracotomy
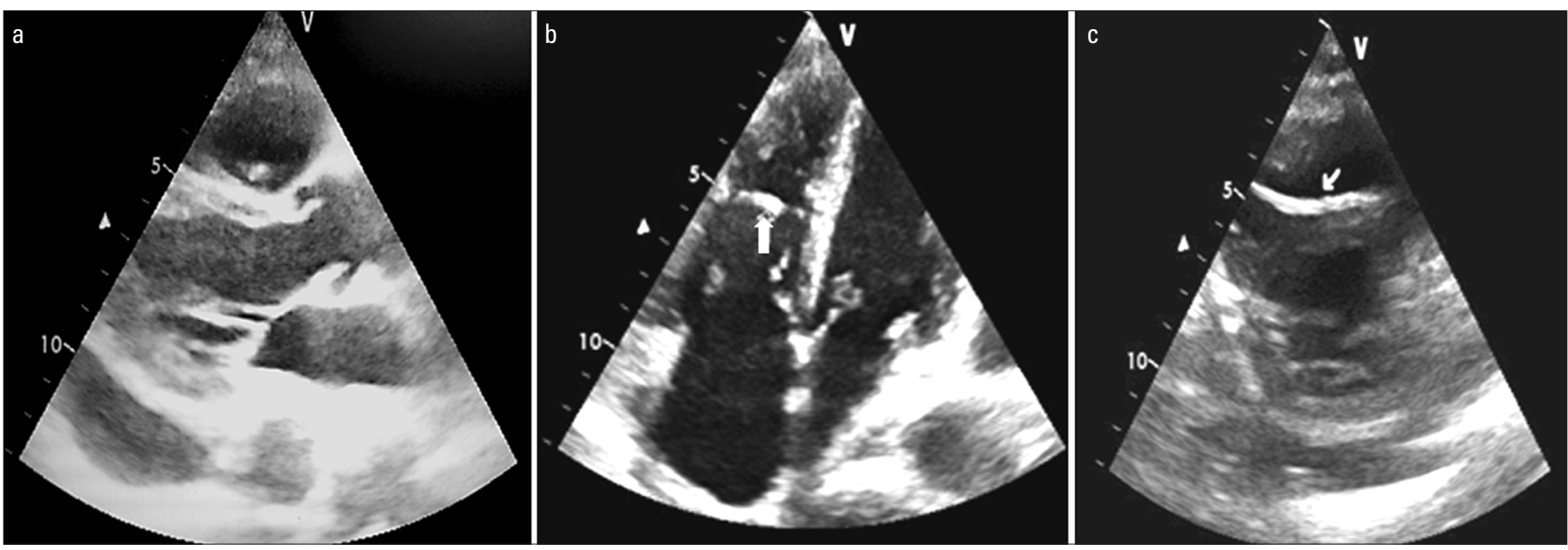

Figure 1. Transthoracic echocardiography showing a large pericardial effusion posterior to the left ventricle in parasternal long-axis view (a), apical four-chamber view (b), and parasternal short-axis view (c) showing a pigtail catheter in the right ventricle (white arrow) 


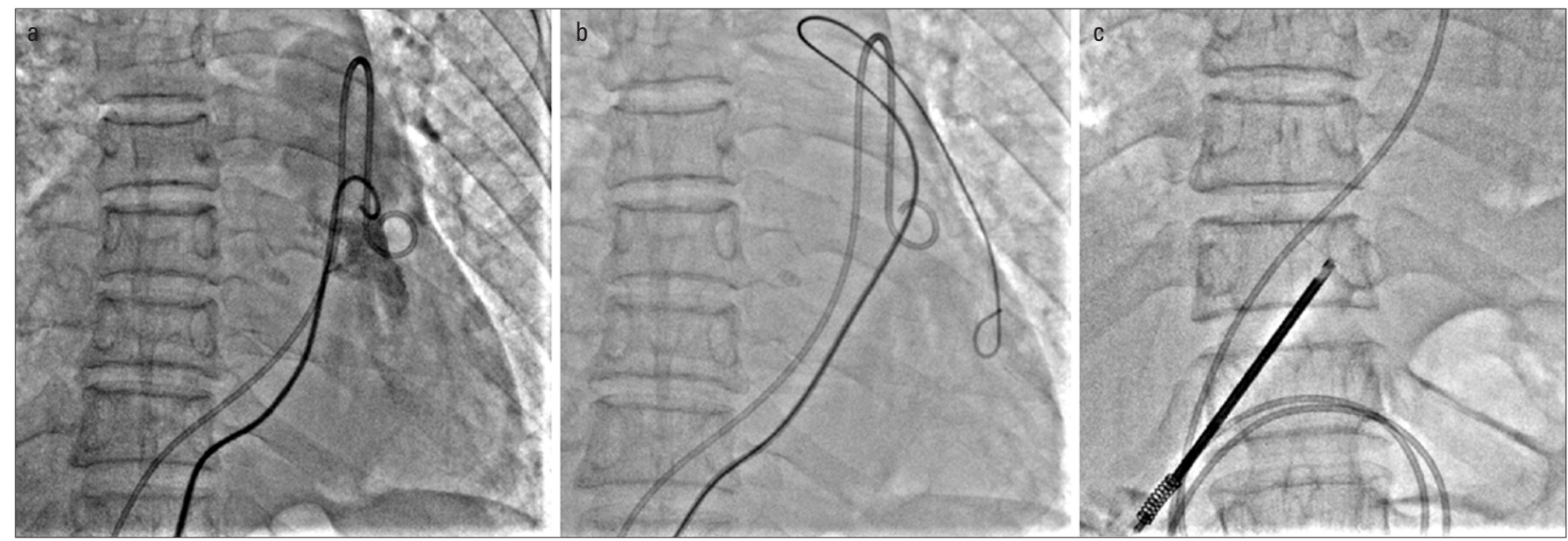

Figure 2. Fluoroscopic image showing 2 pigtail catheters; one in the pulmonary artery (black color, filled with contrast agent) and another one in the pericardial cavity (a). Opacified main pulmonary artery is seen (a). Suture based vascular closure device (Perclose ProGlide ${ }^{\mathrm{TM}}$ ) was tracked through the right ventricle (RV) over the guidewire positioned at the distal, left pulmonary artery (b). The suture knot is tied and trimmed by the knot pusher at RV apex (c)

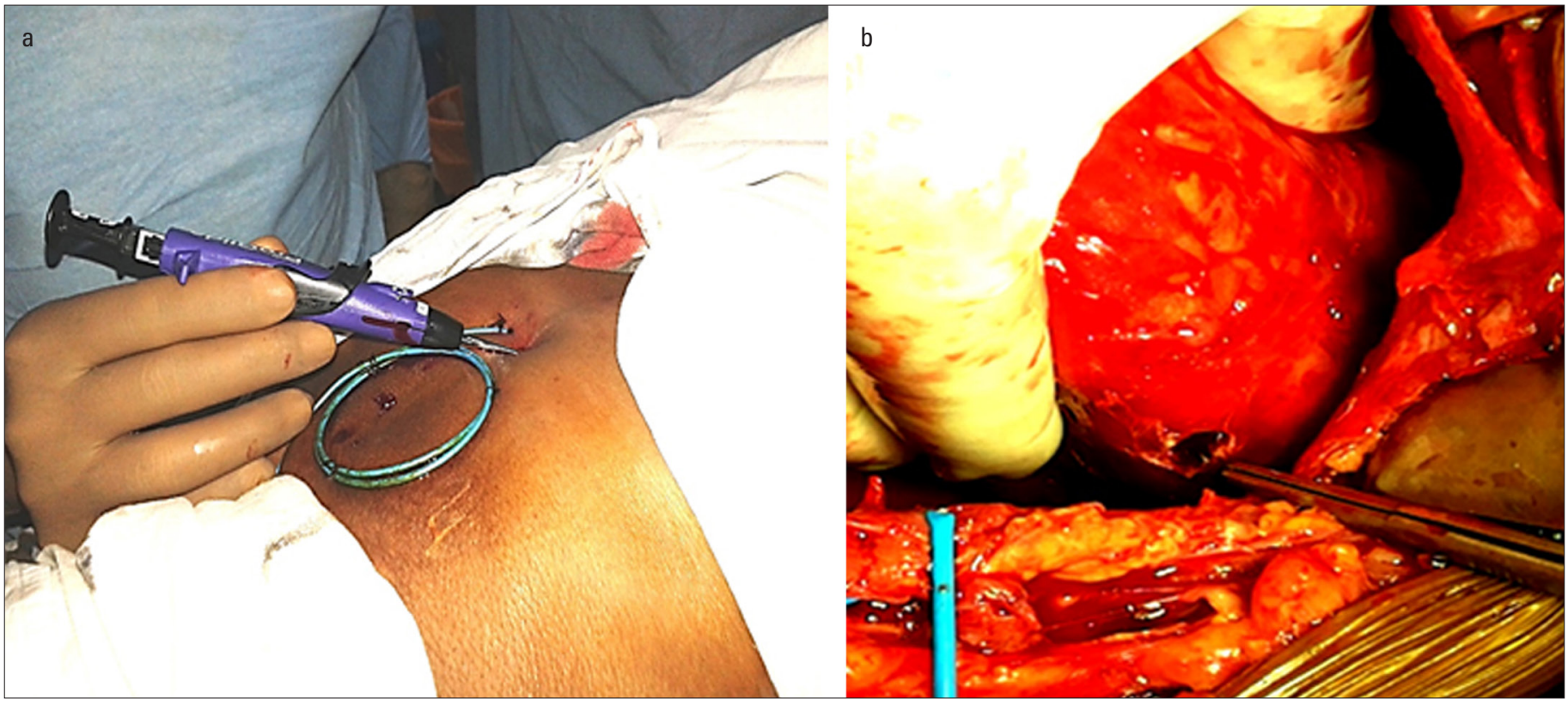

Figure 3. Perclose ProGlide ${ }^{\mathrm{TM}}$ device inserted through subxiphoid space to deliver the knot at the right ventricle (RV) apex (a). The intraoperative image showing a $1 \times 1 \mathrm{~cm}$ rent at the diaphragmatic surface of RV (b)

was performed, and a pleuro-pericardial window was made. Approximately, $100 \mathrm{~mL}$ of clotted blood was removed from the pericardial space. The RV rent of about $1 \times 1 \mathrm{~cm}$ size (Fig. $3 \mathrm{~b}$ ) was repaired with 4-0 Prolene pledgeted suture. The device delivered suture knot was found in the pericardial cavity. She remained hemodynamically stable during the postoperative recovery phase. On day 2 of surgery, she had acute shortness of breath and hypotension secondary to massive pulmonary thromboembolism and succumbed to the illness. Histopathological examination of the pericardial tissue showed metastatic signet ring cell adenocarcinoma. The primary malignancy could not be localized during her lifetime, and the patient's relatives refused an autopsy.

\section{Discussion}

Echocardiography-guided pericardiocentesis is the standard of care for cardiac tamponade. In the Mayo Clinic series of 1,127 patients of echocardiography-guided pericardiocentesis, the procedural success rate was $97 \%$, and the complication rate was $4.7 \%$ (1). A total of $17(1.5 \%)$ patients had cardiac chamber entry/lacerations during pericardiocentesis, of which 5 patients required open surgical repair, and 1 patient died of RV perforation (1). The RV perforation can be life-threatening owing to continued bleeding and tamponade (4). Mortality rates associated with venous catheter perforation can be as high as $65 \%$ (4). Surgical repair of iatrogenic RV perforation is associated with 
high mortality and morbidity because of compromised hemodynamic state, anticoagulation, or associated comorbid illness (4).

Vascular closure devices (VCD) are commonly used following trans-femoral arterial access and are known to improve patient comfort and shorten hospital stay following percutaneous coronary intervention (8). Suture mediated VCD is a simplified knot delivery with a pre-tied knot, which produces mechanical closure and hemostasis $(8,9)$. Their off-label use is usually restricted to atypical vascular sites such as subclavian arteries, common carotid artery, and even descending aorta (9-11). Collagen plug based devices (2-5) and septal occluder devices $(6,7)$ have been used for successful closure of iatrogenic RV perforation. The collagen plug based device was successful even in the closure of right atrial perforation (12). An unsuccessful attempt of RV closure by the septal occlude device is also reported, and the patient finally had an open surgical repair (13). To the best of our knowledge, this is the first attempted case of Perclose ProGlide ${ }^{\mathrm{TM}}$ suture mediated device for closure of RV perforation. Though the effectiveness of the suture based device for RV perforation had been demonstrated in situ cadaveric heart (14), we had an unsuccessful attempt in the index case. The possible mechanism of failure was the friable nature of cardiac muscle owing to which the surgical closure was done over pledgets. As the ventricle is in continuous motion, it is possible that the sutures cut through the muscle layer while being stretched when tying the knot. An enlarged RV rent of $1 \times 1 \mathrm{~cm}$ on surgical exploration was suggestive of tearing of the RV tissue by percutaneous suture knot of VCD. Retrospectively, a backup guidewire could have been placed across the site for orthogonal deployment of the second device, expecting failure of the first one. When withdrawing the device, we could have maintained guidewire access anticipating failure, which we did not do. In hindsight, it is probably wiser to attempt percutaneous closure of ventricular perforations with collagen plug based occlusive devices like Angioseal (2-5) rather than the suture based devices. The predisposing factors for pre-terminal pulmonary thromboembolism were prolonged immobilization and possible hypercoagulable state secondary to underlying malignancy.

\section{Conclusion}

We described a patient with iatrogenic RV perforation, who had open surgical repair of the RV rent following an unsuccessful attempt of percutaneous closure by suture based VCD.

Informed consent: Informed consent was obtained from the patient's family for publication of case details and images. All the procedures performed were in accordance with the ethical Declaration of Helsinki. Perclose ProGlide ${ }^{\mathrm{TM}}$ is an investigational device used for closure of right ventricular perforation.

\section{References}

1. Tsang TS, Enriquez-Sarano M, Freeman WK, Barnes ME, Sinak LJ, Gersh BJ, et al. Consecutive 1127 therapeutic echocardiographically guided pericardiocenteses: clinical profile, practice patterns, and outcomes spanning 21 years. Mayo Clin Proc 2002; 77: 429-36. [Crossref]

2. Petrov I, Dimitrov C. Closing of a right ventricle perforation with a vascular closure device. Catheter Cardiovasc Interv 2009; 74: 24750. [Crossref]

3. Pourdjabbar A, Hibbert B, Hendry P, Labinaz M. Angio-Seal closure of an iatrogenic right ventricular perforation. Clin Res Cardiol 2014; 103: 577-9. [Crossref]

4. Bakos Z, Harnek J, Jenkins N, Johnson T, Strange J, Asimakopoulos G, et al. How should I treat an accidentally misplaced $8 \mathrm{Fr}$ drainage catheter in the right ventricle? Eurolntervention 2014; 10: 768-70. [Crossref]

5. Coughlan JJ, Szirt R, Pearson I, Cosgrave J. Percutaneous closure of an iatrogenic right ventricular perforation with an angio-seal vascular closure device: a case report. Eur Heart J Case Rep 2020; 4: 1-4. [Crossref]

6. Stolt V, Cook S, Räber L, Wani S, Garachamani A, Vogel R, et al. Amplatzer Septal Occluder to treat iatrogenic cardiac perforations. Catheter Cardiovasc Interv 2012; 79: 263-70. [Crossref]

7. Saxena A, Karmakar S, Narang R. Successful Percutaneous Device Closure of Right Ventricular Perforation During Pericardiocentesis. JACC Cardiovasc Interv 2016; 9: e221-2. [Crossref]

8. Noori VJ, Eldrup-Jørgensen J. A systematic review of vascular closure devices for femoral artery puncture sites. J Vasc Surg 2018; 68: 887-99. [Crossref]

9. Lorenzo JF, Rey JV, Arquillo IL, Encisa de Sá JM. Off-label use of Proglide percutaneous closure device in iatrogenic arterial catheterizations: Our experience. Vascular 2020; 28: 756-9. [Crossref]

10. Abbas M, Hamilton M, Yayha M, Angel D, Mwipatayi BP, Sieunarine K. A simple method of closing an iatrogenic subclavian arterial puncture. Indian J Surg 2004; 66: 356-8.

11. Hatfield MK, Zaleski GX, Kozlov D, Woo T, Gentile E, Sinnen J. Angio-seal device used for hemostasis in the descending aorta. AJR Am J Roentgenol 2004; 183: 612-4. [Crossref]

12. Chadha DS, Kumar J R, Mishra SC, Jhamb D. Percutaneous closure of accidental iatrogenic right atrial perforation. IHJ Cardiovascular Case Reports (CVCR) 2018; 2: 184-6. [Crossref]

13. Celik M, Yilmaz Y, Kahyaoglu M, Kup A, Bilen Y, Zehir R. Right ventricular free wall perforation during pericardiocentesis, and an inappropriate device selection for percutaneous treatment. J Card Surg 2021; 36: 336-8. [Crossref]

14. Shah AH, Sharma D, Butany J, Cusimano RJ, Horlick E, Jansen K, et al. CRT-500.02 Perclose Suture Mediated Closure System to Treat Accidental Pericardiocentesis Drain Entry in to the Right Ventricle. J Am Coll Cardiol Intv 2016; 9 (4_Supplement): S53. [Crossref]

Address for Correspondence: Rajesh Vijayvergiya, MD, Department of Cardiology, Advanced Cardiac Centre, Post Graduate Institute of Medical Education\&Research, Chandigarh-India Phone: +91172 2756218

E-mail: rajeshvijay999@hotmail.com

CCopyright 2021 by Turkish Society of Cardiology Available online at www.anatoljcardiol.com DOI:10.5152/AnatolJCardiol.2021.49 